\title{
Development of a Constructive Scheme to Justify the Parameters of a Belt Drive with a Driven Composite Pulley and with Elastic Elements
}

\author{
Dilrabo Mamatova, Anvar Djuraev, Alisher Mamatov, Muhammad Ali Turgunov
}

\begin{abstract}
The article presents a constructive scheme and the principle of operation of the developed belt drive with a composite driven pulley with elastic elements. The technique and electrotsenometric scheme of the experimental setup for changing the loading and driving conditions of the recommended belt drive with composite driven pulleys with a rubber shock absorber are presented. The results of experimental studies on the loading of the shafts and the rotational speed of the transmission pulleys for various rubber grades used in composite pulleys are presented. The results of full-factor experiments to optimize the parameters of a belt drive, as well as the results of production tests of a cleaning machine, in the drive of which the recommended belt drive is used, are presented. Full-factor experiments substantiated the values of the rotational speed of the drum, the tension roller eccentricity and the stiffness coefficient of the elastic element, which provides a high cleaning effect.
\end{abstract}

Keywords: belt drive, composite pulley, rubber bushing, tension roller, torque loading, cotton cleaning efficiency.

\section{INTRODUCTION}

It is important to ensure uniform rotation of the output pulley associated with the working body of the technological machine $[1,2,3,4]$. But, in a number of technological machines, uneven rotation of the working member with the required amplitude and frequency is required. The need for rotation of the driven shaft (working body) with a variable angular velocity is due to the fact that in some technological processes this leads to an increase in the effect of the operation of the machine. For example, the message of the working bodies of uneven rotation improves the quality of loosening and cleaning of fibrous material. For this purpose, belt drives with variable gear ratios [5] are used. Belt gears with variable gear ratio are used as an element of drives of various machines and mechanisms ensuring rotation of the driven shaft with variable angular speed: vibratory machines, machines for processing fibrous and bulk materials, mining and drilling machines, etc.

Revised Manuscript Received on February 05, 2020.

* Correspondence Author

Dr. Dilrabo Mamatova*, Associate Professor, Department of Machine science and service, Tashkent Institute of Textile and Light Industry.

Dr. Anvar Djuraev, Professor, Department of Machine science and service, Tashkent Institute of Textile and Light Industry.

Dr. Alisher Mamatov, Professor, Department of Mathematic and IT, Tashkent Institute of Textile and Light Industry.

Dr. Muhammad Ali Turgunov, Associate Professor, Department of Mechanical and Aerospace Engineering, Turin Polytechnic University in Tashkent.

(c) The Authors. Published by Blue Eyes Intelligence Engineering and Sciences Publication (BEIESP). This is an open access article under the CC BY-NC-ND license (http://creativecommons.org/licenses/by-nc-nd/4.0/)
Resource-saving belt drive modes, the depreciation of the oscillations of the loads by the transmission belt is insufficient. To increase the damping of load oscillations, we recommend a belt drive with a composite driven pulley with an elastic element (Fig. 1). The drive pulley 1 by means of the belt 3 informs the rotation of the driven pulley 2 , causing the tension roller 4 to rotate. Rotational movement from the rim 5 through the annular elastic sleeve 7 is transmitted to the hub 6 rigidly connected with the shaft of the driven pulley 2. During the execution of the technological process, the load on the shaft of the driven pulley 2 changes to the shaft of the machine and further on the leading pulley 1 and on the electric drive.

In this case, the peak values of the moment of resistance (load) are depreciated by an annular elastic sleeve 7. By choosing the necessary elastic-dissipative properties (rubber material), you can control the degree of depreciation of the peak values of the load. At the same time, the rotational movement of the rim 5 of the driven pulley 2 is sufficiently smoothed out. But, obtaining the movement of the pulley 2 with the necessary law of variation of the angular velocity can be obtained with a change in the eccentricity of the tension roller. If the eccentric tensioning roller 4 is made composite with an elastic sleeve, then the law of motion of the output pulley will be more complex.

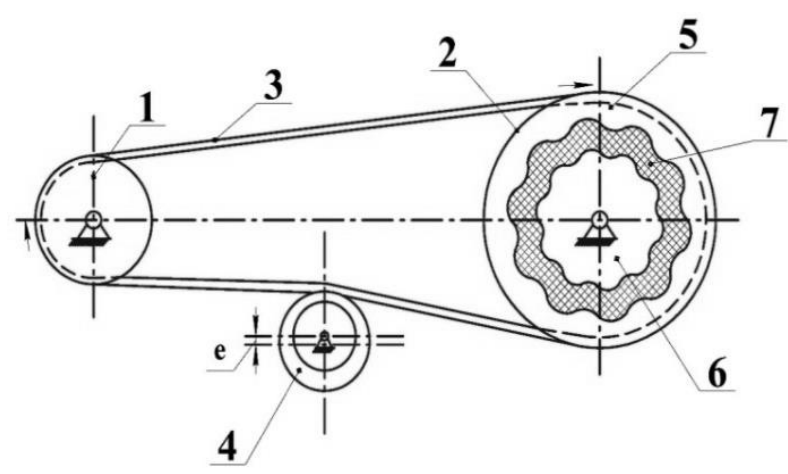

Fig1. Belt drive with integral driven pulley and eccentric elastic tension roller.

\section{METHODS AND RESULTS OF THEORETICAL STUDIES}

In the process of transferring the belt, the belt slip along the pulleys changes and the belt tension also changes. With a change in the tension of the belt, the deformation of the elastic bushing of the tensioning roller also changes. This leads to a decrease in the working radius of the tensioning roller. 


\section{Development of a Constructive Scheme to Justify the Parameters of a Belt Drive with a Driven Composite Pulley and with Elastic Elements}

There is an alignment of the belt tension, leading to a uniform rotation of the pulleys of the belt drive. In this case, the determination of the kinematic characteristics of the belt transmission is important. Consider the kinematics of a belt drive at a certain displacement (assuming constant) of the rim 1 of the tensioning roller due to the deformation of the elastic sleeve 2 by the value " $\Delta$ " (see Fig. 2,a). Then, in fact, the axis of rotation of the outer sleeve (rim) 1 moves upwards by the value " $\Delta$ " relative to axis 4 (see Fig. $2, b$ ). With constant belt tension, the " $\Delta$ " distance also remains constant during belt drive operation. But, changing the tension of the belt leads to a change in the position of the axis $C_{1}$.For a belt drive with a tension roller, the kinematic relations from $[6,7]$ take place:

$$
U_{1,2}=\frac{n_{1}}{n_{2}}=\frac{\omega_{1}}{\omega_{2}} ; U_{1,3}=\frac{n_{1}}{n_{2}}=\frac{\omega_{1}}{\omega_{3}} ; \quad U_{2,3}=\frac{n_{2}}{n_{3}}=\frac{\omega_{2}}{\omega_{3}}
$$

where, $n_{1}, n_{2}, n_{3}$ - the number of revolutions per minute, respectively, leading, driven pulleys and tensioning roller, $\omega_{1}, \omega_{2}, \omega_{3}$ - angular velocity, respectively, leading, driven pulleys and tensioning roller.
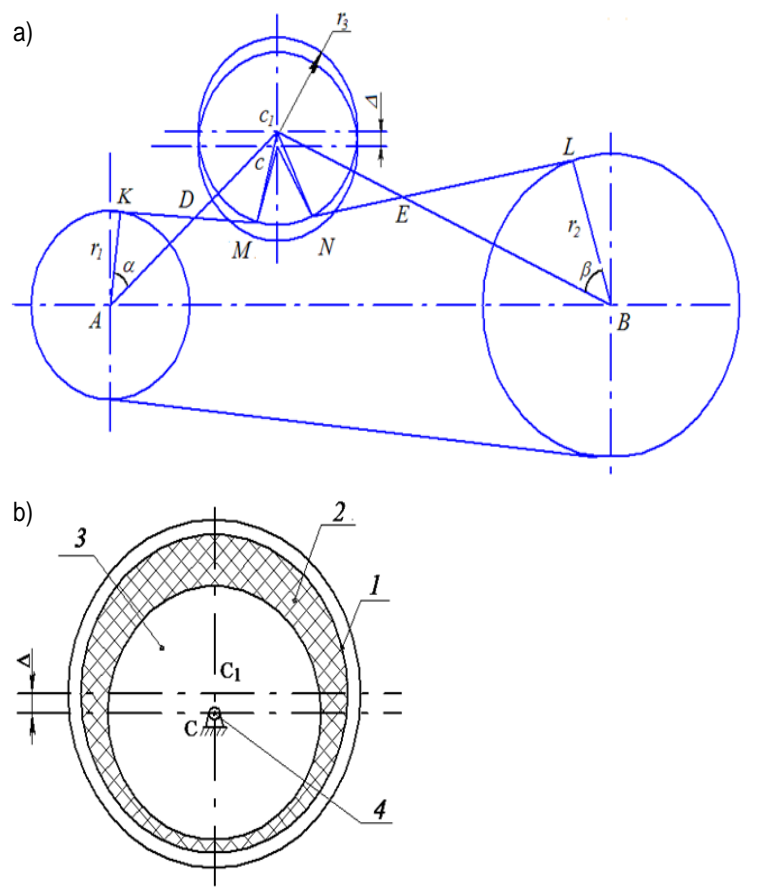

Fig. 2. a) the scheme of a belt drive with a composite tension roller, b) tension roller, with the offset position of the outer sleeve due to deformation of the elastic sleeve 2 .

According to the theory of motion transmission in belt transmissions, taking into account the corresponding calculation scheme in (Fig. 2,a) you can write:

$$
\frac{\omega_{1}}{\omega_{3}}=\frac{C_{1} D}{A D} ; \frac{\omega_{2}}{\omega_{3}}=\frac{C_{1} E}{B E}
$$

In this case, from $\Delta \mathrm{AKD}$ and $\Delta \mathrm{BLE}$ we have:

$$
\cos \alpha=\frac{A K}{A D}=\frac{r_{1}}{A D} ; \cos \beta=\frac{B L}{B E}=\frac{r_{2}}{B E}
$$

From (Fig. 3,a) we get:

$$
C_{1} D=A C_{1}-A D ; \quad C_{1} E=B C_{1}-B E
$$

Taking into account (3), we rewrite (2) in the following form:

$$
\frac{\omega_{1}}{\omega_{3}}=\frac{A C_{1} \cos \alpha-r_{1}}{r_{1}} ; \frac{\omega_{2}}{\omega_{3}}=\frac{B C_{1} \cos \beta-r_{2}}{r_{2}}
$$

In the absence of movement of the rim axis of the tensioning roller:

$$
r_{1}+r_{3}=A C_{1} \cos \alpha ; r_{2}+r_{3}=B C_{1} \cos \beta
$$

When moving the axis of the rim of the belt pulley tensioner, $r_{3,1}$ and $r_{3,2}$ the polar radii of the tensioner pulley will change due to changes in the position of the tensioner pulley.

From $\triangle M C M_{1}$ and $\triangle N C N_{1}$ in (Fig. 3) we can define:

$$
r_{3,1}=\frac{M M_{1}}{\cos \gamma_{1}} ; r_{3,2}=\frac{N N_{1}}{\cos \gamma_{2}}
$$

where, $r_{3,1}, r_{3,2}$ - polar radius tension roller; $\gamma_{1}$ - the angle between the radius $r_{3}$ and $r_{3,1} ; \gamma_{2}$ - the angle between the radius $r_{3}$ and $r_{3,2}$;

From (Fig. 3,b) you can see that:

$$
\Delta^{2}-C_{1} \mathrm{M}_{1}^{2}=r_{3,1}^{2}-M M_{1}^{2} ; C_{1} M_{1}=r_{3}-M M_{1}
$$

Given $M M_{1}=r_{3,1} \cos \gamma$,we determine from (7) the polar radius of the tension roller:

$$
r_{3,1}=r_{3} \cos \gamma_{1}+\sqrt{r_{3}^{2}\left(\cos ^{2} \gamma_{1}-1\right)+\Delta^{2}}
$$

In a similar way, we obtain an expression for determining the second polar radius of the tension roller:

$$
r_{3,2}=r_{3} \cos \gamma_{2}+\sqrt{r_{3}^{2}\left(\cos \gamma_{2}-1\right)+\Delta^{2}}
$$

In this case, respectively, the angles and are determined from the expressions:

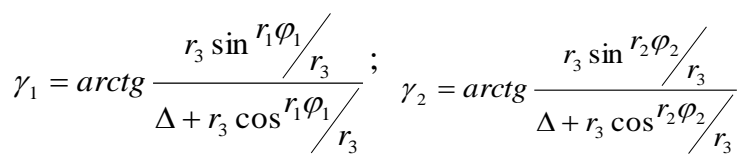

where, $r_{1}, r_{2}$ are the radius of the drive and driven pulleys, $\varphi_{1}, \varphi_{2}$ are the angular displacements of the drive and driven pulleys. 
a)

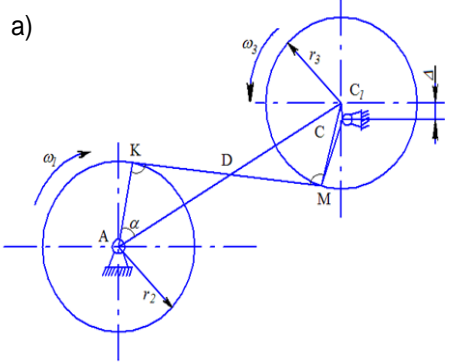

b)
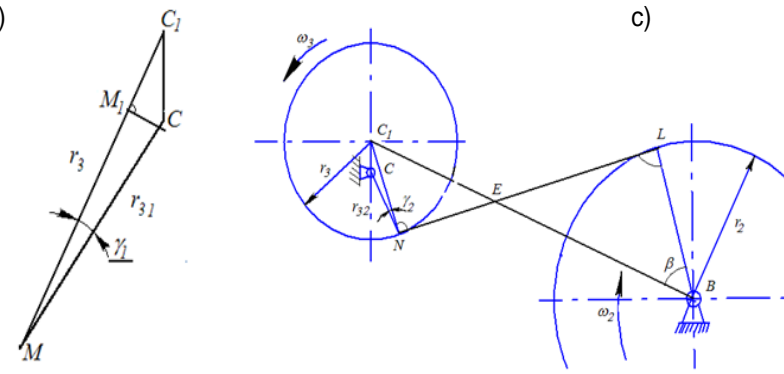

Fig. 3.The design of the belt drive with a composite tensioning roller

where, $a$ - the scheme of transfer of the movement from the leading pulley to the tension roller; $b$ - geometry of the location of the tensioning roller; $c$ - the scheme of kinematics between the tension roller and the driven pulley Substituting (8), (9) and (10) into (5) we get the expressions:

$\cos \alpha=\frac{1}{A C_{1}}\left[r_{1}+r_{3} \cos \left(\operatorname{arctg} \frac{r_{3} \sin \frac{r_{1} \varphi_{1}}{r_{3}}}{\Delta+r_{3} \cos \frac{r_{1} \varphi_{1}}{r_{3}}}\right)+\sqrt{r_{3}^{2}\left[\cos ^{2}\left(\operatorname{arctg} \frac{r_{3} \sin \frac{r_{1} \varphi_{1}}{r_{3}}}{\Delta+r_{3} \cos \frac{r_{1} \varphi_{1}}{r_{3}}}\right)-1+\Delta^{2}\right]}\right.$

$\cos \beta=\frac{1}{\mathrm{BC}_{1}}\left[r_{2}+r_{3} \cos \left(\operatorname{arctg} \frac{r_{3} \sin \frac{r_{2} \varphi_{2}}{r_{3}}}{\Delta+r_{3} \cos \frac{r_{2} \varphi_{2}}{r_{3}}}\right)+\sqrt{\left.r_{3}^{2}\left[\cos ^{2}\left(\operatorname{arctg} \frac{r_{3} \sin \frac{r_{2} \varphi_{2}}{r_{3}}}{\Delta+r_{3} \cos \frac{r_{2} \varphi_{2}}{r_{3}}}\right)+\Delta^{2}\right]\right]}\right.$

The values obtained $\cos \alpha$ and $\cos \beta$ from (11) substituting in (4) we obtain the gear ratios $U_{1,3}$ and $U_{2,3}$.

In this case $U_{1,3} / U_{2,3}=U_{1,2}$, taking into account, we obtain a gear ratio for a belt drive with a composite tension roller in the form:

$$
U_{1,2}=\frac{r_{3} \cos \left(\operatorname{arctg} \gamma_{1}\right)+\sqrt{r_{3}^{2}\left(\cos ^{2} \gamma_{1}-1\right)+\Delta^{2}}}{r_{3} \cos \left(\operatorname{arctg} \gamma_{2}\right)+\sqrt{r_{3}^{2}\left(\cos ^{2} \gamma_{2}-1\right)+\Delta^{2}}} \cdot \frac{r_{2}}{r_{1}}
$$

Substituting the expression (12) into (1) we obtain the formula for determining the angular velocity of the driven pulley with a composite tension roller:

By deriving the derivative of expression (13), one can obtain a formula for determining the angular acceleration of the driven pulley of the belt drive in question. Determinations of the kinematic characteristics of the transmission, taking into account numerical valuesand solving the problem we used Excel. On the basis of the

$$
\omega_{2}=\frac{r_{3} \cos \left(\operatorname{arctg} \gamma_{2}\right)+\sqrt{r_{3}^{2}\left(\cos ^{2} \gamma_{2}-1\right)+\Delta^{2}}}{r_{3} \cos \left(\operatorname{arctg} \gamma_{1}\right)+\sqrt{r_{3}^{2}\left(\cos ^{2} \gamma_{1}-1\right)+\Delta^{2}}} \cdot \frac{\omega_{1} r_{1}}{r_{2}}
$$

solution of the problem, the laws of change in the angular velocity, the angular acceleration of the driven pulley, and the transmission ratio of the belt drive were obtained. At the same time, the main variable parameters of the belt transmission were the radius and movement of its axis due to the deformation of the elastic element of the tensioning roller.

In (Fig. 4) shows the patterns of change in the angular velocity $\Delta$ of the driven pulley from a change in the value of the tensioning pulley of a belt drive.

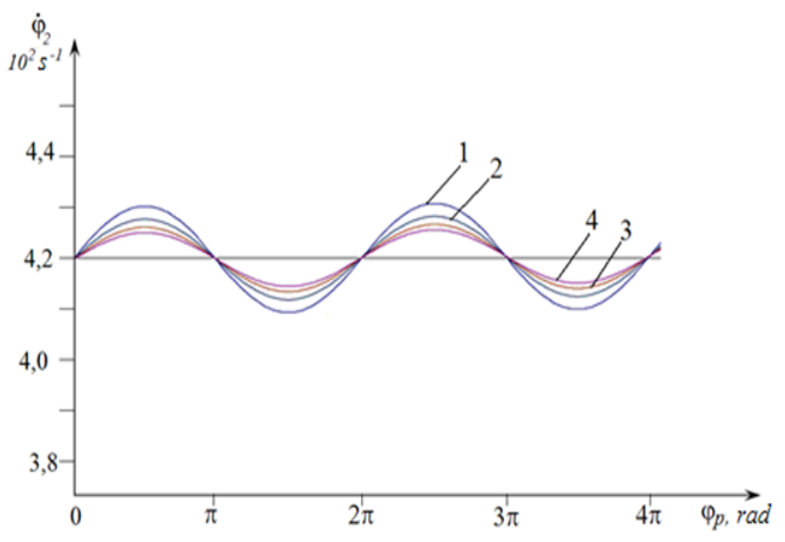

where, $1-\Delta=0.5 \mathrm{~mm} ; 2-\Delta=1.0 \mathrm{~mm} ; 3-\Delta=1.5 \mathrm{~mm} ; 4-\Delta=2.0 \mathrm{~mm}$;

Fig. 4. Patterns of change in the angular velocity of the

\section{driven pulley from a change in the value $\Delta$ of the tensioning roller}

Analysis of the changes $\dot{\varphi}_{2}$ in (Fig. 4) shows that an increase in the vertical movement of the tension roller leads to an increase in the amplitude of oscillations of the angular velocity.

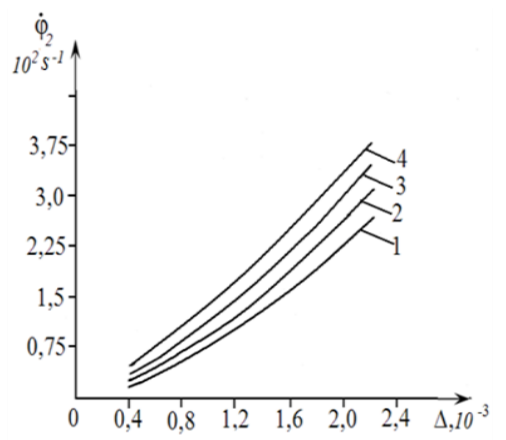

where $1-r_{p}=3.0 \cdot 10^{-2}, 2-r_{p}=3.5 \cdot 10^{-2}, 3-r_{p}=4.0 \cdot 10^{-2}, 4-r_{p}=4.5 \cdot 10^{-2}$

Fig. 5. Dependences of the change in the amplitude of oscillations of the angular velocity of the driven pulley as a function of the magnitude of the deformation of the elastic element of the belt pulley tensioning roller

So, with $\Delta=0,5 \mathrm{~mm}$, the amplitude of oscillation $A_{\dot{\varphi}_{2}}$ reaches $28 \mathrm{~s}^{-1}$, and with $\mathrm{mm}$, the amplitude of oscillations of the angular velocity $\Delta=2,0$ mmof the driven pulley increases to $98 \mathrm{~s}^{-1}$. The average angular velocity is $\dot{\phi}_{2}=4,2 \cdot 10^{2} \mathrm{~s}^{-1}$. 

Pulley and with Elastic Elements

The maximum value of the angular velocity corresponds to $\varphi_{p}=\pi / 2$, and the minimum value to $\varphi_{p}=3 \pi / 2$. With an increase in the radius of the tensioning roller, the oscillation frequency of the angular velocity decreases. Deformation in specific calculations, the value of $\Delta$ is assumed constant. For different stiffness's of the rubber sleeve, $\Delta$ is different (see Fig. 4).

(Fig. 5) shows the obtained graphical dependences of the change in the oscillation range of the angular velocity of the driven pulley on the variation of displacement at various values of the tension roller radius. The increase in the radius of the tensioning roller leads to an increase $\Delta \dot{\varphi}_{2}$ in displacement, thereby to an increase in non-linear patterns. Therefore, in order to change the radius of the tensioning roller does not affect the swing of the angular velocity of the driven pulley, it is necessary to increase the displacement

$\Delta$ (deformation of the elastic sleeve) of the tensioning roller by the corresponding value [8]. To reduce the range of oscillations of the angular velocity of the driven pulley within certain limits, it is advisable to choose $\Delta \leq(1.5 \div 2.3)$ $10^{-3} \mathrm{~m}$

\section{III.NEW RESEARCH METHODOLOGY}

The purpose of the experimental research is to determine the dependence of the influence of the parameters of the composite tensioning roller with an elastic element on the change in the torque of the drive and driven shaft, the change in the frequency of their rotation, taking into account the slippage of the belt.

During the development of the experimental setup, a number of shortcomings were excluded, the previous experimental constructions that were not taken into account used for research. The experimental setup allowed the measurements to be carried out in the operation of the machine with simultaneous processing of the obtained results on a computer, for which the LTR-154 type digital converter was used [9].

In most of the above studies, strain gauging with strain gauges pasted on shafts is used for measuring torque on the drive shafts $[10,11]$. But, in our case, the shafts have a cantilever part, and with this method it became necessary to develop a device that allows measurements with minimal error [9]. The structural scheme of such a device is shown in (Fig. 6). The device consists of a hub 1 for mounting on a shaft and transmitting torque to a pulley 3 mounted on a rolling bearing 2 . Two leashes 4 are attached to the hub on one of which are load cells 5 . Drivers $4 \mathrm{~s}$ one side of the grooves is recessed 6 in the drive pulley, and on the other side mounted on the hub1. To transfer the force to the shaft or from the shaft to the pulley, the leash 4 is simultaneously a drive and a beam for sticking the strain gauges.

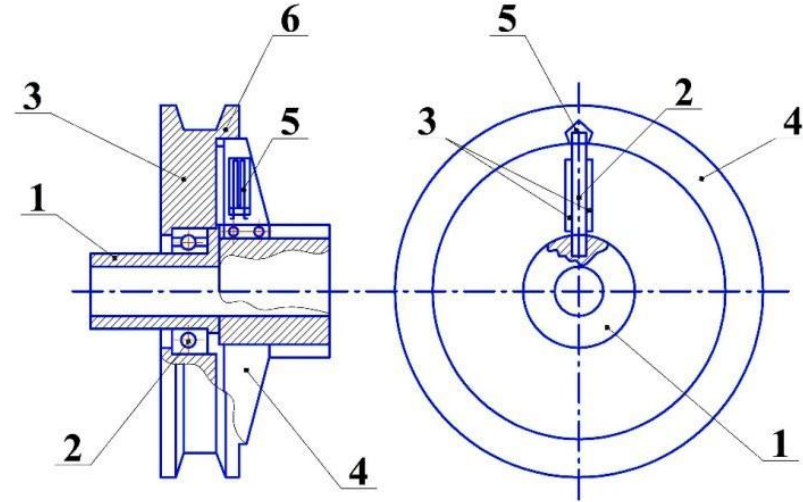

Fig. 6. Torque meter circuit

1 - hub for installation on the shaft; 2 - rolling bearing; 3 pulley; 4 - habits with load cells pasted on it; 5 - strain gauges; 6 - groove for installing the beam.

On the hub 1 by means of rolling bearing 2 is installed a pulley 3 for a belt drive. The pulley 3 mounted on the rolling bearing 2 has the ability to rotate around an axis within the elasticity of the beam 6 with load cells pasted on it 5 . Since the beam is a leash 4 for the pulley 3 , one end of which is fixed to the hub 1 and the other horses enter the groove 6 , milled on the rim of the pulley 4 . From the impact, the beam 6 bends as the torque transmitted by this gear increases, leading to a change in the parameters (resistance) of the strain gauges 5 pasted on the leash 4 .

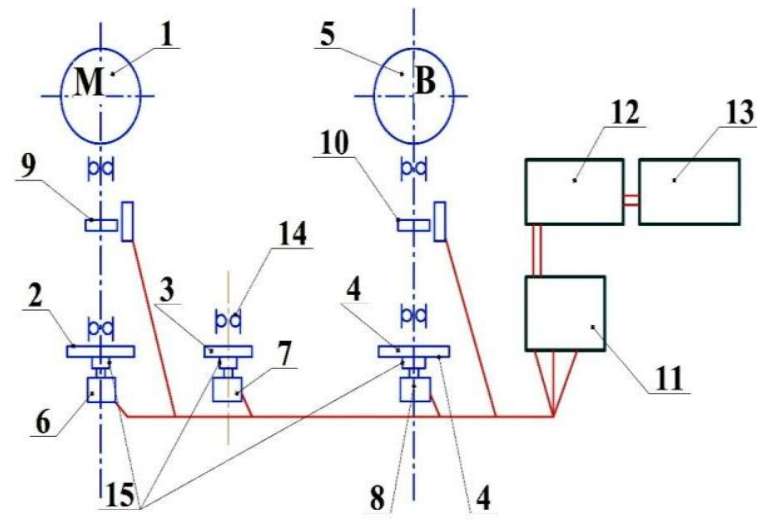

Fig. 7. Measuring installation flow chart

1 - electric motor, 2 - drive pulley, 3 - tensioning pulley, 4 - driven pulley, 5-brake, 6-7-8 current collectors, 9-10 Hall sensors with impellers, 11 - tensometric amplifier UT-4-

1,12 - digital LTR converter -154, 13 - computer.

After the corresponding Drawings are calculated on the computer the true values of the torque transmitted by the belt drive.

The electric circuit of measurement was accepted classical with the converter of digital type and the amplifier which circuit is shown in (Fig. 7).

According to the results of the experiments, oscillograms were obtained that characterize the angular velocity of the drive pulley shaft, torques on the shafts of the driving and driven pulleys and the loading axis of the transmission tension roller. 


\section{IV.RESULTS AND DISCUSSION}

According to the results of the experiments, oscillograms were obtained characterizing the angular velocity of the shaft of the driving pulley, torques on the shafts of the driving and driven pulleys and the loading axis of the tensioning transfer roller. Analysis of the load law of the shaft of the driven composite pulley with an elastic shock absorber compared to the loading of the shaft of the driven pulley of the existing belt drive showed that the peak torque values in the recommended version of the belt drive is reduced 1.5 2.0 times. This allows the necessary uniformity of movement of the working body of the technological machine, as well as reducing the loading of the electric drive. It should be noted that if it is necessary to ensure the required unevenness of rotation of the output shaft, we recommend changing the eccentricity of the tensioning roller of the recommended belt transmission (or stiffness of the rubber sleeve of the tensioning roller).

The analysis of the obtained oscillograms shows that with an increase in the eccentricity of the tension roller, the amplitudes of the oscillations of the tension of the tension roller axis and the torques on the pulley shafts and the angular velocity of the driving pulley increase.

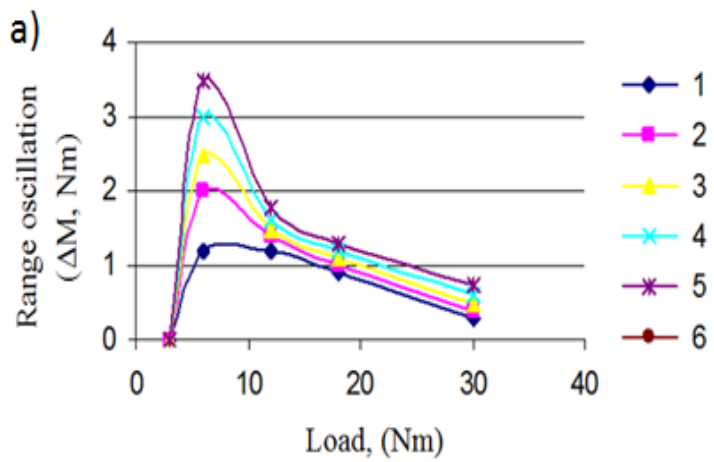

$1-\mathrm{e}=1 \mathrm{~mm} ; 2-\mathrm{e}=2 \mathrm{~mm} ; 3-\mathrm{e}=3 \mathrm{~mm} ; 4-\mathrm{e}=4 \mathrm{~mm}$

Fig. 8, a).Graphs of dependence of $\Delta M$ on the transmitted load at different values of the tension roller's eccentricity (mixing of the roller axis, $\Delta=e$ )

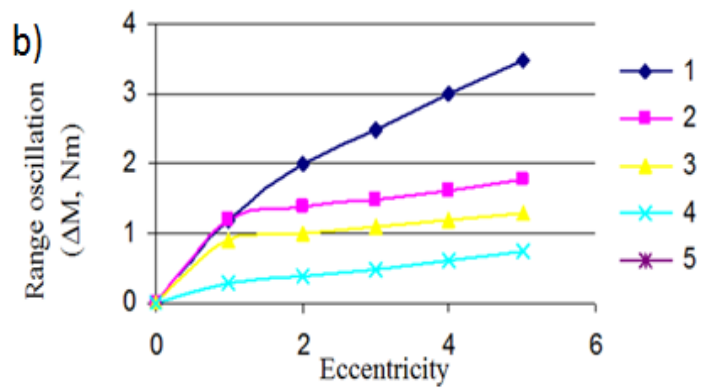

$1-\mathrm{M}=6 \mathrm{Nm}, 2-\mathrm{M}=12 \mathrm{Nm}, 3-\mathrm{M}=18 \mathrm{Nm}, 4-\mathrm{M}=30 \mathrm{Nm}$

Fig. 8, b)Plots of changes in the magnitude of the torque oscillations on the driven pulley shaft on the change in the eccentricity (or shift of the axis) of the tension roller The dependence of the load on the axis of the tension roller from the change in the values of eccentricity

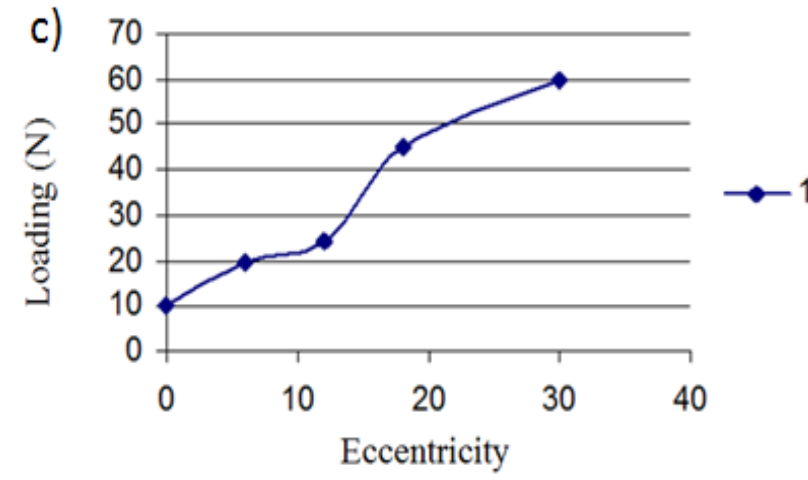

Fig. 8. Parameter dependencies

where, a) the scheme of transfer of the movement from the leading pulley to the tension roller; b) geometry of the

location of the tensioning roller; c) the scheme of kinematics between the tension roller and the driven pulley

For the recommended belt drive, it is important to obtain the law of motion of the driven pulley with the required change in angular velocity, which allows efficient execution of the technological process by working bodies associated with the driven pulley shaft. Figure 8 presents the resulting graphs based on waveform processing. The value of the eccentricity of the tension roller is taken as a constant value of the deformation of the elastic roller sleeve, that is, $\Delta=\mathrm{e}$.

Fig.8, c).Analysis of graphs in (Fig. 8,a) shows that an increase in eccentricity from $1.0 \mathrm{~mm}$ to $5.0 \mathrm{~mm}$ leads to torque fluctuations on the driven pulley shaft, the span of which $\Delta M$ reaches $1.2 \mathrm{Nm}$ with a technological resistance of $12 \mathrm{Nm}$, and under load $M_{c}=30 \mathrm{Nm}, \Delta M$ comes to $2.5 \mathrm{Nm}$. At the same time, the load on the tension roller axis increases to $60 \mathrm{~N}$ with a roller eccentricity of $2.5 \mathrm{~mm}$ (Fig. $8, b)$.

Considering the working conditions of a cottoncleaning machine, in the drive of which a recommended belt drive with a tension roller with eccentricity $(2.5 \div 3.5) \mathrm{mm}$ is installed. It is important to study the effect of deformation of the rubber roller sleeve $(\Delta)$ or eccentricity (e). In (Fig.9) shows the experimentally obtained graphical dependencies. With an increase in eccentricity, the swing of the torque on the driven pulley shaft increases to 3.45 Nmwithan eccentricity of the tensioning roller $5.0 \mathrm{~mm}$.

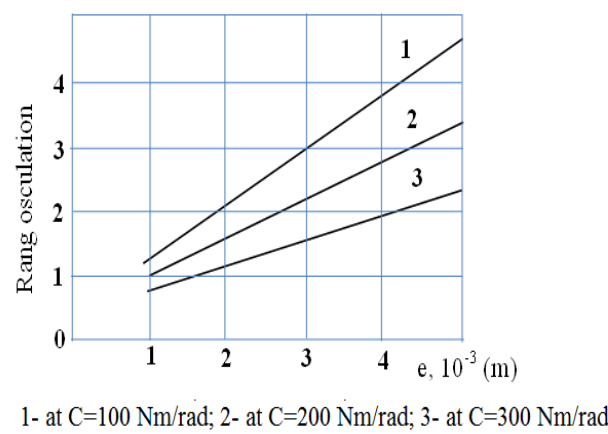

Fig. 9. Dependences of the change in torque on the drive shaft on the eccentricity of the tensioning roller for various values of the circular stiffness of rubber 


\section{Development of a Constructive Scheme to Justify the Parameters of a Belt Drive with a Driven Composite Pulley and with Elastic Elements}

The experiments were carried out in a cotton-cleaning unit, in the drive of which the recommended belt drive was used. Table 1 presents the intervals of change of input factors $[12,13]$. For the output parameter, the cleaning effect of raw cotton was chosen.

Table 1.Based on the calculations, the regression equation has the following form:

\begin{tabular}{|c|c|c|c|c|c|c|c|}
\hline \multirow[b]{2}{*}{$\begin{array}{l}\text { Nameoffa } \\
\text { ctors }\end{array}$} & \multirow[b]{2}{*}{$\begin{array}{c}\text { Characterenc } \\
\text { oding }\end{array}$} & \multicolumn{5}{|c|}{ Truevaluefactors } & \multirow[b]{2}{*}{$\begin{array}{c}\text { Changeinte } \\
\text { rval }\end{array}$} \\
\hline & & $\begin{array}{c}- \\
1,6 \\
82\end{array}$ & -1 & 0 & +1 & $\begin{array}{c}+1,6 \\
82\end{array}$ & \\
\hline $\begin{array}{l}\text { Nose } \\
\text { drum } \\
\text { rotation } \\
\text { frequenc } \\
\text { y, rpm }\end{array}$ & $\mathrm{X}_{1}$ & 387 & $\begin{array}{c}40 \\
0\end{array}$ & $\begin{array}{c}44 \\
0\end{array}$ & $\begin{array}{c}48 \\
0\end{array}$ & 507 & 40 \\
\hline $\begin{array}{l}\text { Eccentri } \\
\text { city (or } \\
\text { displace } \\
\text { ment } \Delta \\
\text { of the } \\
\text { axis) of } \\
\text { the } \\
\text { tensioni } \\
\text { ng roller } \\
\text { with an } \\
\text { elastic } \\
\text { element, } \\
\text { mm. }\end{array}$ & $\mathrm{X}_{2}$ & $\begin{array}{c}0,3 \\
6\end{array}$ & 1 & 3 & 5 & 6,4 & 2 \\
\hline $\begin{array}{l}\text { The } \\
\text { stiffness } \\
\text { coefficie } \\
\text { nt of the } \\
\text { elastic } \\
\text { element } \\
\text { (rubber), } \\
\text { Nm/rad. }\end{array}$ & $\mathrm{X}_{3}$ & 84 & $\begin{array}{c}10 \\
0\end{array}$ & $\begin{array}{c}15 \\
0\end{array}$ & $\begin{array}{c}20 \\
0\end{array}$ & 234 & 50 \\
\hline
\end{tabular}

$$
\begin{aligned}
& Y=41,46+1,087 x_{1}-1,23 x_{2}+0,78 x_{3}-0,29 x_{1} x_{2}-0,075 x_{1} x_{3}- \\
& -0,068 x_{2} x_{3}-1,47 x_{1}^{2}-1,77 x_{2}^{2}-0,94 x_{3}^{2}
\end{aligned}
$$

After determining the significance of the coefficients, the regression equation has the form:

$Y=41,46+1,087 x_{1}-1,23 x_{2}+0,78 x_{3}-1,47 x_{1}^{2}-1,77 x_{2}^{2}-0,94 x_{3}^{2}$

The resulting regression equation on the basis of the Fisher test was checked for adequacy. The calculated value of the Fisher criterion was determined from the following expression

$$
\begin{gathered}
F_{c r i}=\frac{S_{a d}^{2}(Y)}{S^{2}(\bar{Y})} ; \\
S_{a d}^{2}=\frac{\sum_{1}^{20}\left(y_{u}-\overline{y_{0}}\right)^{2}-\sum_{1}^{6}\left(y_{0 i}-\overline{y_{0}}\right)}{20-6-5}=\frac{0,44-0,377}{9}=0,005 ;
\end{gathered}
$$

$$
F_{c a l}=\frac{S_{a d}^{2}}{S_{\{y\}}^{2}}=\frac{0.005}{0.079}=0.074
$$

When comparing the table value of the Fisher criterion $F_{t a b}$ with the calculated value of $F_{c a l}$, the condition $F_{c a l}=$ $0.074<3.48=F_{t a b}$ is satisfied and the adequacy is determined. The tabular value of the Fisher criterion we get on the following requirement from the application:

$F_{\text {tab }}=\left[P_{D}=0,95 ; f\left\{S_{\text {ad }}^{2}\{Y\}\right\}=20-6-(6-1)=9 ; f\left\{S_{M}^{2}\right\}=6-1=5\right]=3,48$

The numerical solution of the equations was performed on a computer using the EXCEL program and graphical dependencies of the parameters were obtained (Fig.10)

Charts based on regression equations show that a change in the frequency of rotation of the drum affects the cleaning efficiency of raw cotton. Graph 1 (Fig.10, a) shows the effect of input parameters at lower values $\mathrm{x}_{2}=1 \mathrm{~mm}$ and $\mathrm{x}_{3}=100 \mathrm{Nm} / \mathrm{rad}$ on the cleaning effect of cotton. With a revolving drum speed of $400 \mathrm{rpm}$, the cleaning effect was $36.6 \%$; it was observed that with a further increase in the rotation speed, the cleaning effect also increased. When the rotational speed of the drum was $456 \mathrm{rpm}$, the highest cleaning effect was achieved39.2\%.
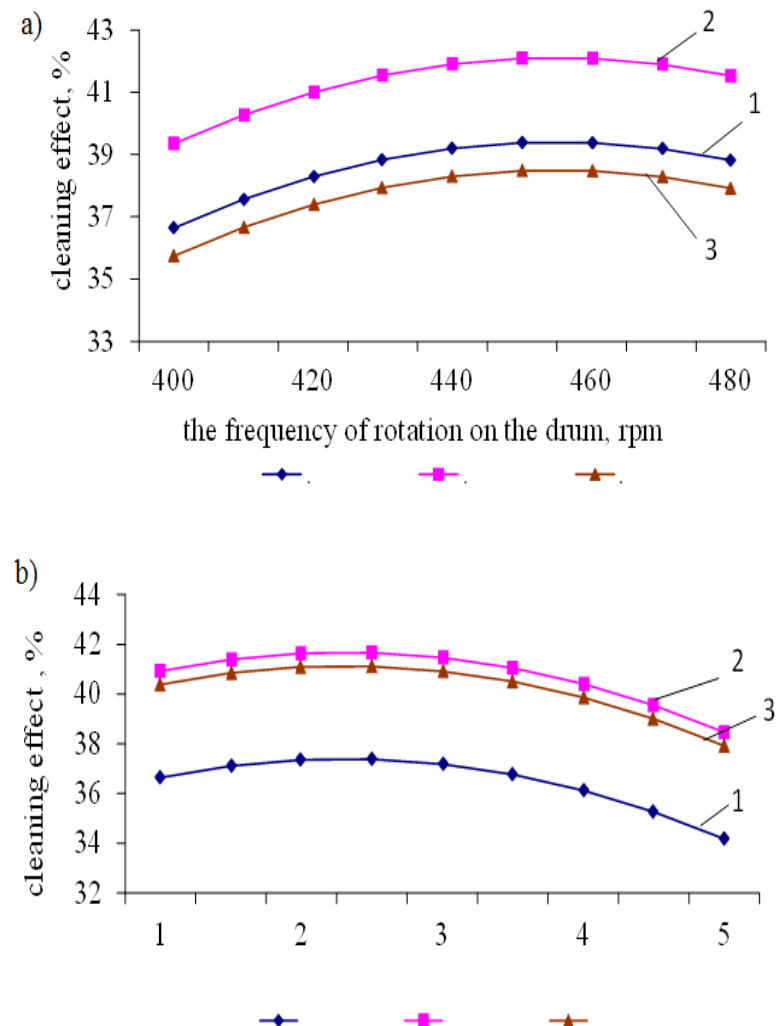

Blue Eyes Intelligence Engineering 


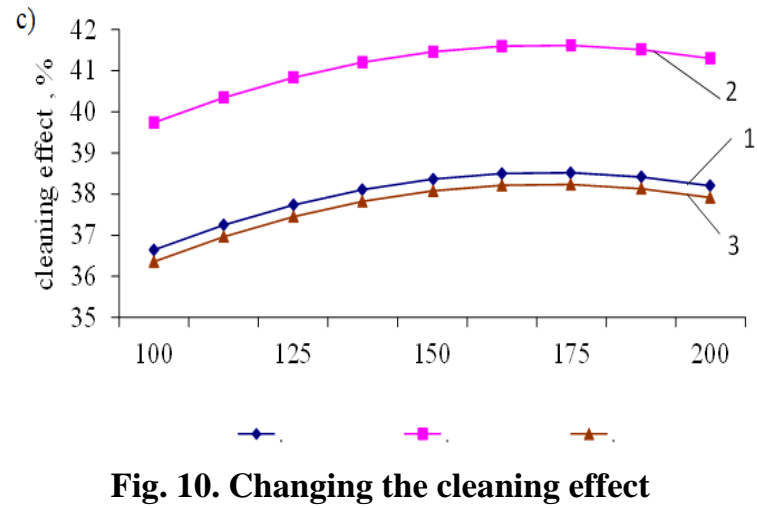

$a$ - the cleaning effect depending on the rotational speed of the drum, $b$ - changes in the cleaning effect depending on the eccentricity of the tensioning roller with an elastic element, $c$ - changes in the cleaning effect depending on the elastic coefficient of the elastic element.

With an increase in the frequency of rotation from 456 rpm to $480 \mathrm{rpm}$, the cleaning effect is reduced to $38.8 \%$. On the graph 2 (Fig. 10,a), the results of the change in the cleaning effect depending on the input factors for $\mathrm{x}_{2}=3 \mathrm{~mm}$ and $x_{3}=150 \mathrm{Nm} / \mathrm{rad}$ are shown. When the rotational speed of the drum is $400 \mathrm{rpm}$, the cleaning effect was $38.9 \%$. With a further increase in the rotational speed, the cleaning effect also increases. When the rotational speed of the drum was $456 \mathrm{rpm}$, the cleaning effect was the highest and amounted to $41.8 \%$. With an increase in the rotational speed to 480 $\mathrm{rpm}$, the cleaning effect decreased and amounted to $41.1 \%$.

Fig. 10,a shows the results of the change in the cleaning effect depending on the input parameters for the largest values $\mathrm{x}_{2}=5 \mathrm{~mm}$ and $\mathrm{x}_{3}=200 \mathrm{Nm} / \mathrm{rad}$. At the same time, when the rotational speed of the drum was $400 \mathrm{rpm}$, the cleaning effect was the lowest and was $35.8 \%$, with a further increase in the rotation speed of the drum, the cleaning effect also increased. At a rotational speed of 456 $\mathrm{rpm}$, the cleaning effect increased to $38.7 \%$. With an increase in the rotational speed to $480 \mathrm{rpm}$, the cleaning effect was $38 \%$. The rotational speed of $456 \mathrm{rpm}$, the cleaning effect reached the highest value of $41.8 \%$. Graphical dependences of the change in the cleaning effect of cotton depending on the eccentricity (Fig. 10,b) and on the elastic coefficient of the rubber bushing of the roller (Fig. 10,c) were also obtained. It follows from the above that the coefficient of elasticity of an elastic element affects the cleaning effect. The greatest cleaning effect was achieved when the coefficient of elasticity is $175 \mathrm{Nm} / \mathrm{rad}$ and this value is optimal $[14,15,16]$.

Based on the full-factor experiments, it follows that when using cleaning machines with recommended parameters, a high cleaning effect can be achieved. Consequently, the optimum values of the parameters of the cleaning machine were found: the rotational speed of the drum barrel is $456 \mathrm{rpm}$, the eccentricity of the tensioning roller with the elastic element is $2.5 \mathrm{~m}$, and the elastic coefficient of the elastic element is $175 \mathrm{Nm} / \mathrm{rad}$. With these parameters, the highest cleaning effect was achieved, which was $41.8 \%$.

\section{CONCLUSION}

A new resource-saving design scheme of a belt drive with a variable gear ratio has been developed. The problem of kinematics of a belt drive with a variable gear ratio with an eccentric tensioning roller with an elastic sleeve has been solved. Experiments substantiated system parameters. The laws governing changes in the load of the shafts of the belt drive are determined. The graphic dependences of changes in the swing torque range on the shaft of the driven belt drive pulley from different values of the eccentricity of the tensioning roller, and from the external technological load when the rotational speed and stiffness of the rubber shock absorber are built. The regularities of tensioning roller loading with changing values of eccentricity are obtained. The technique and electrostatic scheme of the experimental setup for changing the loading and driving conditions of the recommended belt drive with a composite driven pulley with a rubber shock absorber is presented. Full-factor experiments substantiated the values of the rotational speed of the drum, the tension roller eccentricity and the coefficient of circular stiffness of the elastic element, which provides a high cleaning effect. The results of the production tests of the cleaning machine, in the drive of which the recommended belt drive is used, are presented.

\section{REFERENCES}

1. Gramblicka, S., Kohar, R., Stopka, M. (2017). Dynamic analysis of mechanical conveyor drive system. ProcediyaEngineering, 192, 259264.

2. M. di Napoli, Strahle M., Ruzimov S. (2016). Intelligent belt drive systems in hybrid. IFAC-PapersOnLine. 49-21, 47-53.

3. Atsumi T. (2016). Relationship between flying-height and trackingposition control with thermal actuators for magnetic heads in HDDs. IFAC-PapersOnLine. 49-21, 26-31.

4. Vetyukov Yu., Eliseev V., Krommer M. (2015). Modeling the dynamics of a flexible belt drive using with discontinuities, IFACPapers OnLine. 48-1, 604-609.

5. Sun C., Ren A., Sun G., Liu Yo. (2011). The calculation of the classical v-belt life with different reliability, Procediya Engineering15, 5290-5293.

6. Djuraev A., MaksudovR.Kh.,Turdaliev V.M. (2013). Kinematic and dynamic analysis of belt transmissions with variable transmission ratios", Monograph. Ed. "Science", 168.

7. Mamatova D., Ergashov M., Salimov M. (2007). Belt Drive Patent R. Uz. No. IAP 03341. BulletinNo 4.

8. Mamatova D., Djuraev A., etc. (2011). Belt transfer Patent R.Uz. № UZ FAP 00645 bullet No 8.

9. Mamatova D., Djuraev A. and others. (2011). Belt transfer Patent R.Uz. № UZ FAP 00676 bulletin No 12.

10. Svetlitsky V.A., Stassenko I.V. (1973). Collection of problems on the theory of oscillations. Highschool, M., 456.

11. Mamatova D.A., DjuraevA. (2017). Analysis of Changes in Tension in Leading Branch Belt Drive. JournalofTextileScience\&Engineering, Volume 7, Issue 1, 1-3.

12. Tikhomirov V.B. (1974). Analysis and planning of the experiment on the research in textile industry. M. Lightandtextileindustry, 262.

13. Mamatova D.A., DjuraevA. (2016). Analysis of Belting Stiffness Transmission Impact on Rotating Mass Motion Law of Technological Machines, Journal of Machinery Manufacturing and Automation (JMMA), Vol.lss.1, 15-20.

14. Mamatova D.A., DjuraevA. (2018). The Basis of Theoretical Parameters in Belt Drive with Variable Transmission Ratio. IJARSET, Volume 5, Issue 9, 6770-6777.

15. Mamatova D.A., Djuraev A. (2015). Theoretical definition of the stiffness of the composite element of the composite driven pulley of the transmission, European Applied Sciences Europaischefachhochschule No 9, 40-42

16. Mamatova D.A., DjuraevA. (2017). The analysis of change belt tension in the slack side of belt transmission, European Science Review Austria. "East West" Association for Advanced Studies and Higher EducationGmbH,No 1-2, 204-207. 
AUTHORS PROFILE

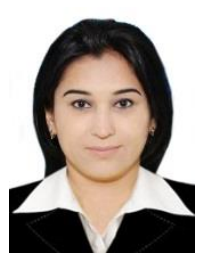

Dr. DilraboMamatova, Associate Professor, Department of Machine science and service, Tashkent Institute of Textile and Light Industry.

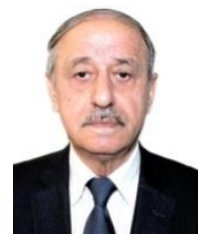

Dr. AnvarDjuraev, Professor, Department of Machine science and service, Tashkent Institute of Textile and Light Industry.

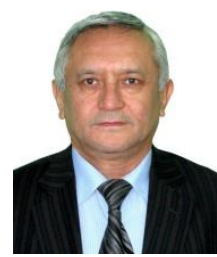

Dr. AlisherMamatov, Professor, Department of Mathematic and IT, Tashkent Institute of Textile and Light Industry.

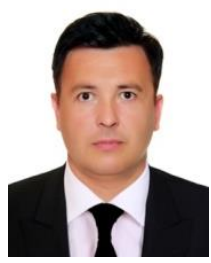

Dr.Muhammad Ali Turgunov, Associate Professor, Department of Mechanical and Aerospace Engineering, Turin Polytechnic University in Tashkent. 